\title{
Application of a modified graphene nanosheet paste electrode for voltammetric determination of methyldopa in urine and pharmaceutical formulation
}

\author{
Hadi Beitollahi ${ }^{{ }^{*}}$, Somayeh Tajik², Malek Hossein Asadi ${ }^{3}$ and Pourya Biparva ${ }^{4}$
}

\begin{abstract}
Background: Electrochemical sensors and biosensors for pharmaceutical, food, agricultural and environmental analyses have been growing rapidly due to electrochemical behavior of drugs and biomolecules and partly due to advances in electrochemical measuring systems. In the present work, we describe the preparation of a new electrode composed of graphen (G) modified with 2,7-bis(ferrocenyl ethyl) fluoren-9-one (2,7-BFGPE) and investigate its performance for the electrocatalytic determination of methyldopa in aqueous solutions.
\end{abstract}

Methods: Experimental section was carried out using cyclic voltammetry, square wave voltammetry and chronoamperometry.

Results: Under the optimized conditions ( $\mathrm{pH} 7.0)$, the square wave voltammetric peak current of methyldopa increased linearly with methyldopa concentration in the ranges of $9.0 \times 10^{-8}$ to $5.0 \times 10^{-4} \mathrm{M}$. The detection limit was $5.0 \times 10^{-8} \mathrm{M}$ methyldopa. The diffusion coefficient $\left(\mathrm{D}=9.35 \times 10^{-6} \mathrm{~cm} 2 / \mathrm{s}\right)$ and electron transfer coefficient $(a=0.52)$ for methyldopa oxidation were also determined.

Conclusions: The method shows the development of a sensor for selective and sensitive determination of methyldopa. This sensor was successfully applied to determine the methyldopa in some real samples.

Keywords: Methyldopa; Graphene nanosheets; Modified electrode; Voltammetry; Electrochemical sensor

\section{Background}

Methyldopa is an antihypertensive agent that is used in the treatment of high blood pressure or hypertension, especially when it is complicated with renal disease. Its antihypertensive properties are primarily due to its action on the central nervous system. Methyldopa inhibits the enzyme DOPA decarboxylase, which converts L-DOPA into dopamine, and is a precursor for norepinephrine and subsequently epinephrine. It is converted to $\alpha$-methyl norepinephrine in adrenergic nerve terminals, and its antihypertensive action appears to be due to its stimulation of central adrenal receptors, which reduces sympathetic tone

\footnotetext{
*Correspondence: h.beitollahi@yahoo.com

'Environment Department, Institute of Science and High Technology and Environmental Sciences, Graduate University of Advanced Technology, P.O. Box 76315-117, Kerman, Iran

Full list of author information is available at the end of the article
}

and produces a fall in blood pressure. The therapeutic concentration of methyldopa in human plasma is usually in the range of 0.1 to $0.5 \mathrm{mg} \mathrm{L}^{-1}$, and its average terminal elimination half-life is $2 \mathrm{~h}$ (Kwan et al. 1976; Myhre et al. 1982). Clearly, detection and quantification of methyldopa is an important feature in pharmaceutical and clinical procedures (Rezaei et al. 2013; Gholivand and Amiri 2013). Several analytical procedures have been reported for the analysis of methyldopa in bulk form, pharmaceutical form, or biological fluids. These include titrimetry, chromatography, kinetic methods, spectrophotometry, and H NMR. However, these methods have disadvantages, including high costs, long analysis times, the requirement of complex and tedious sample pretreatments, and, in some cases, a low sensitivity and selectivity, that make them unsuitable for a routine analysis. On the other hand, electrochemical methods have attracted great interest because of 
their simplicity, rapidness, and high sensitivity in detecting methyldopa and various other analytes without requiring tedious pretreatments (Athanasiou-Malaki and Koupparis 1984; Tajik et al. 2013a; Shahrokhian and Rastgar 2011; Molaakbari et al. 2014; Moccelini et al. 2011).

The use of carbon paste as an electrode was initially reported in 1958 by Adams. In afterward researches, a wide variety of modifiers including enzymes, polymers, and nanomaterials have been used with these versatile electrodes. Carbon paste electrodes (CPEs) are widely applicable in both electrochemical studies and electroanalysis, thanks to their advantages such as very low background current (compared to solid graphite or noble metal electrodes), facility to prepare, low cost, large potential window, simple surface renewal process, and easiness of miniaturization. Besides the advantageous properties and characteristics listed previously, the feasibility of incorporating different substances during paste preparation (which results in the so-called modified carbon paste electrode) allows the fabrication of electrodes with desired composition and, hence, with predetermined properties (Tajik et al. 2013b; Khoobi et al. 2013; Mokhtari et al. 2012; Díaz et al. 2013; Gholivand and Mohammadi-Behzad 2014; Mazloum-Ardakani et al. 2010; Thomas et al. 2013a; Raoof et al. 2007; Dönmez et al. 2014; Raoof et al. 2006a).

Electrochemical methods using chemically modified electrodes (CMEs) have been widely used as sensitive and selective analytical methods for the detection of trace amounts of biologically important compounds. One of the most important properties of CMEs is their ability to catalyze the electrode process via the significant decrease of overpotential with respect to the unmodified electrode. With respect to the relatively selective interaction of the electron mediator with the target analyte in a coordinated fashion, these electrodes are capable of considerably enhancing the selectivity of electroanalytical methods (Beitollahi et al. 2011a; Luo et al. 2013; Taleat et al. 2008; Huo et al. 2013; Thomas et al. 2013b; Raoof et al. 2006b; Oliveira et al. 2013; Beitollahi et al. 2011b; Thomas et al. 2013c; Mohammadi et al. 2013; Sanghavi et al. 2013; Beitollahi et al. 2014; Li et al. 2012; Ghoreishi et al. 2012; Yildiz et al. 2014).

As a new kind of two-dimensional carbon material, graphene has attracted increasing attention due to its unique properties including high surface area, excellent electrical conductivity, quick electron mobility at room temperature, high mechanical strength, and ease for functionalization (Joon et al. 2014). Graphene-based electrochemical sensors have been proved to possess excellent electrocatalytic ability and good performances (Ping et al. 2014; Ma et al. 2014; Silva et al. 2014; Zhu et al. 2013; Sun et al. 2012; Xi et al. 2013).

In the present work, we describe the preparation of a new electrode composed of graphene $(G)$ modified with 2,7-bis(ferrocenyl ethyl)fluoren-9-one (2,7-BFGPE) and investigate its performance for the electrocatalytic determination of methyldopa in aqueous solutions.

\section{Methods}

\section{Apparatus and chemicals}

The electrochemical measurements were performed with an Autolab potentiostat/galvanostat (PGSTAT-302 N, Eco Chemie, Utrecht, The Netherlands). The experimental conditions were controlled with General Purpose Electrochemical System (GPES) software. A conventional threeelectrode cell was used at $25^{\circ} \mathrm{C} \pm 1^{\circ} \mathrm{C}$. An $\mathrm{Ag} / \mathrm{AgCl} / \mathrm{KCl}$ $(3.0 \mathrm{M})$ electrode, a platinum wire, and 2,7-BFGPE were used as the reference, auxiliary, and working electrodes, respectively. A Metrohm 691 pH/Ion Meter (Utrecht, The Netherlands) was used for $\mathrm{pH}$ measurements.

All solutions were freshly prepared with double-distilled water. Methyldopa and all other reagents were of analytical grade from Merck (Darmstadt, Germany). Graphite powder and paraffin oil (DC 350, density $=0.88 \mathrm{~g} \mathrm{~cm}^{-3}$ ) as the binding agent (both from Merck) were used for preparing the pastes. The buffer solutions were prepared from orthophosphoric acid and its salts in the $\mathrm{pH}$ range of 2.0 to 11.0. 2,7-BF was synthesized in our laboratory as reported previously (Raoof et al. 2006a).

\section{Synthesis of graphene nanosheets}

Graphene nanosheets were synthesized from natural graphite flakes based on the modified Hummers and Offeman's method (Hummers and Offeman 1958). In a typical synthesis process, $1.0 \mathrm{~g}$ of pristine graphite flakes was immersed in $50 \mathrm{~mL}$ of formic acid and then sonicated for $2 \mathrm{~h}$ at room temperature. The resulting graphite plates were washed with acetone and then dried in an oven at $95^{\circ} \mathrm{C}$ for $12 \mathrm{~h}$. Then, $100 \mathrm{~mL} \mathrm{H}_{2} \mathrm{SO}_{4}$ (95\%) was added into a 500-mL flask and cooled by immersion in an ice bath followed by stirring. About $1.0 \mathrm{~g}$ of treated graphite powder and $0.5 \mathrm{~g}$ $\mathrm{NaNO}_{3}$ were added under vigorous stirring to avoid agglomeration. After the graphite powder was well dispersed, $3 \mathrm{~g} \mathrm{KMnO}_{4}$ was added gradually under stirring and cooling so that the temperature of the mixture was maintained below $10^{\circ} \mathrm{C}$. The mixture was stirred for $2 \mathrm{~h}$ and diluted with deionized double-distilled water (in an ice bath). After that, $25 \mathrm{~mL} 15 \% \mathrm{H}_{2} \mathrm{O}_{2}$ was slowly added to the mixture until the colour of the mixture changed to brilliant yellow, indicating fully oxidized graphite. The as-obtained graphite oxide slurry was re-dispersed in deionized double-distilled water and then exfoliated to generate graphene oxide nanosheets by sonication for $2 \mathrm{~h}$. Then, the solution was filtered and washed with diluted $\mathrm{HCl}$ solution to remove metal ions. Finally, the product was washed with deionized double-distilled water until the solution became acid free and dried under vacuum at $50^{\circ} \mathrm{C}$. A typical transmission 


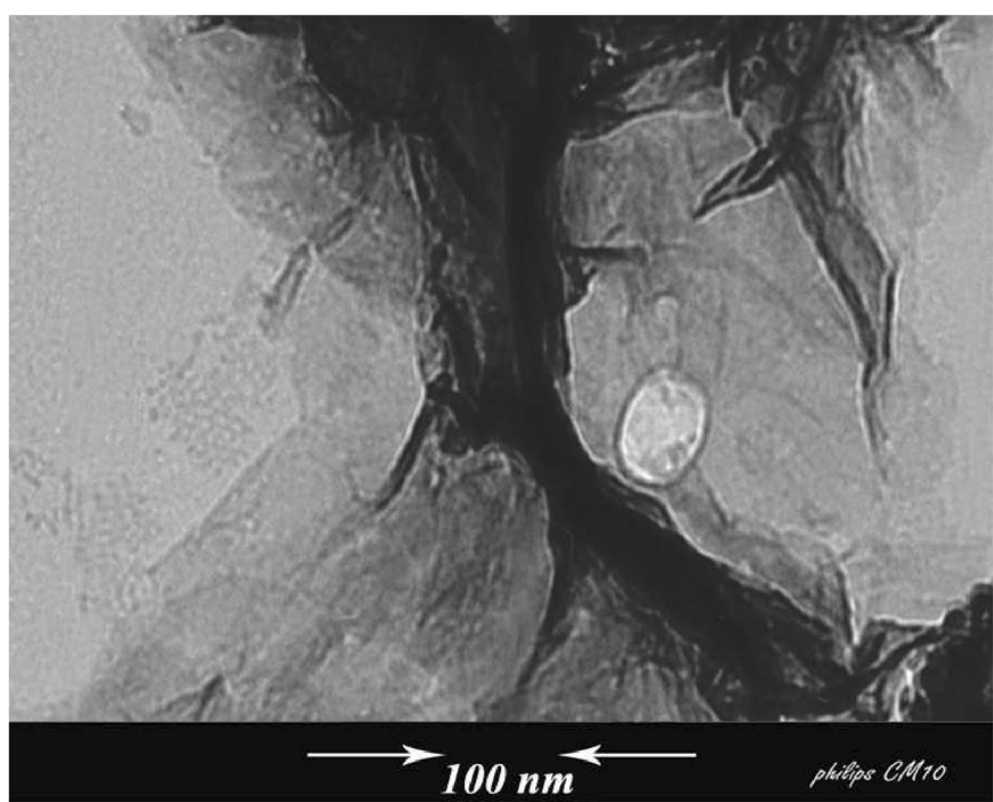

Figure 1 TEM image of the synthesized graphene nanosheets.

electron microscopy (TEM) image of the synthesized graphene nanosheets is shown in Figure 1.

\section{Preparation of the electrode}

2,7-BFGPEs were prepared by hand-mixing $0.01 \mathrm{~g}$ of 2,7$\mathrm{BF}$ with $0.89 \mathrm{~g}$ graphite powder and $0.1 \mathrm{~g} \mathrm{G}$ with a mortar and pestle. Then, approximately $0.7 \mathrm{~mL}$ of paraffin was added to the above mixture and mixed for 20 min until a uniformly wetted paste was obtained. The paste was then packed into the end of a glass tube (ca. $3.4 \mathrm{~mm}$ i.d. and $10 \mathrm{~cm}$ long). A copper wire inserted into the carbon paste provided the electrical contact. When necessary, a new surface was obtained by pushing an excess of the paste out of the tube and polishing with a weighing paper.

For comparison, 2,7-BF-modified CPE (2,7-BFCPE) without G, G paste electrode (GPE) without 2,7-BF, and unmodified CPE in the absence of both 2,7-BF and $\mathrm{G}$ were also prepared in the same way.

\section{Results and discussion}

\section{Electrochemical behavior of 2,7-BFGPE}

2,7-BFGPE was constructed and its electrochemical properties were studied in a $0.1 \mathrm{M}$ phosphate-buffered saline (PBS; pH 7.0) by cyclic voltammetry (CV). The experimental results show well-defined and reproducible anodic and cathodic peaks related to the 2,7-bis(ferrocenyl ethyl)fluoren-9-one/2,7-bis(ferricenium ethyl)fluoren-9-one redox system, with $E_{\mathrm{pa}}, E_{\mathrm{pc}}$, and $E^{\circ}$ of 320,260 , and $290 \mathrm{mV}$ vs. $\mathrm{Ag} / \mathrm{AgCl} / \mathrm{KCl}(3.0 \mathrm{M})$ respectively. The observed peak separation potential $\left(\Delta E_{\mathrm{p}}=E_{\mathrm{pa}}-E_{\mathrm{pc}}\right)$ of $60 \mathrm{mV}$ was greater than the value of $59 / \mathrm{n} \mathrm{mV}$ expected for a reversible system (Bard and Faulkner 2001), suggesting that the redox couple of 2,7-BF in 2,7-BFGPE has a quasi-reversible behavior in aqueous medium.

In addition, the long-term stability of 2,7-BFGPE was tested over a 3-week period. When CVs were recorded after the modified electrode was stored in atmosphere at room temperature, the peak potential for methyldopa oxidation

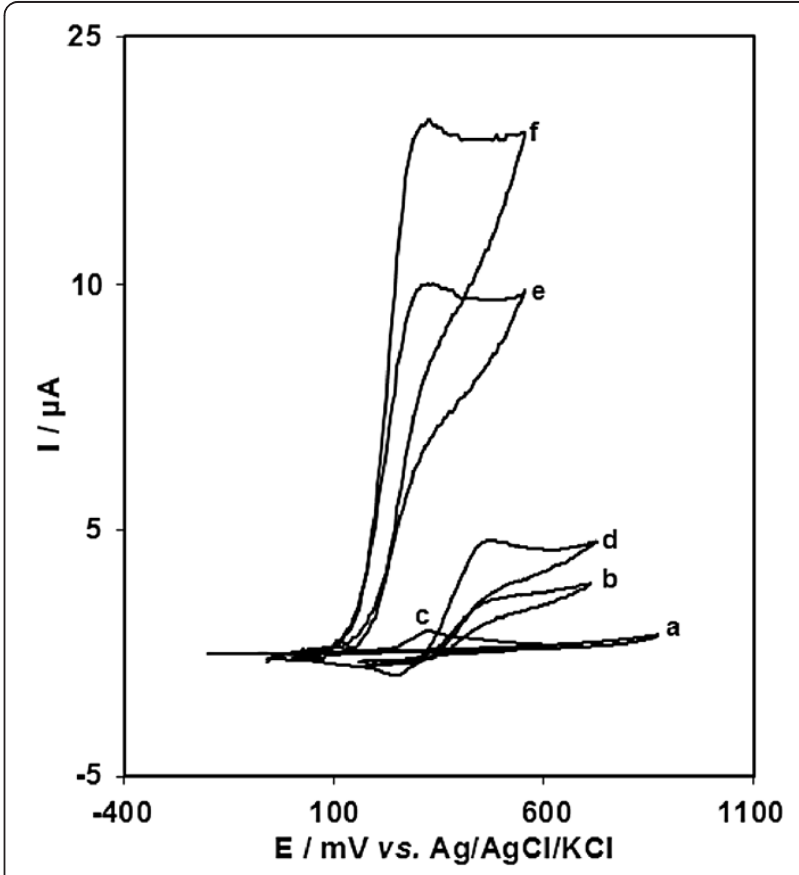

Figure $2 \mathrm{CV}$ responses. (a) Unmodified CPE in $0.1 \mathrm{M} \mathrm{PBS}(\mathrm{pH}$ 7.0) at scan rate of $10 \mathrm{mV} \mathrm{s}^{-1}$. (b) As (a) $+0.35 \mathrm{mM}$ methyldopa. (c) As (a) at the surface of 2,7-BFGPE. (d) As (b) at the surface of GPE. (e) As (b) at the surface of 2,7-BFCPE. (f) As (b) at the surface of 2,7-BFGPE. 


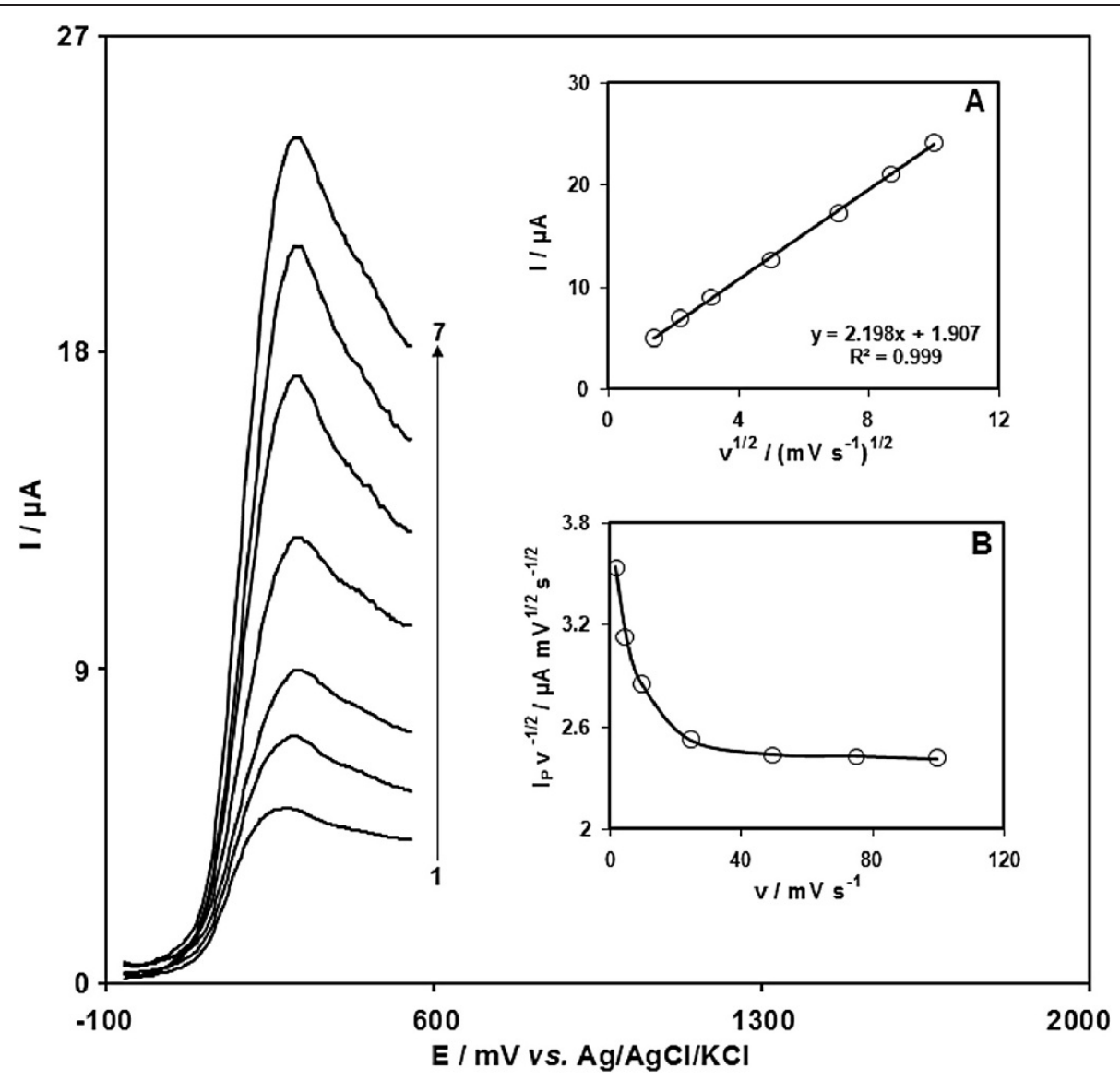

Figure 3 LSVs of 2,7-BFGPE in $0.1 \mathrm{M}$ PBS (pH 7.0) containing $\mathbf{2 0 . 0} \mu \mathrm{M}$ methyldopa at various scan rates. Numbers 1 to 7 correspond to 2 , $5,10,25,50,75$, and $100 \mathrm{mV} \mathrm{s}^{-1}$, respectively. Insets: Variation of (A) anodic peak current vs. $v^{1 / 2}$ and (B) normalized current $\left(I_{\mathrm{p}} / v^{1 / 2}\right) \mathrm{vs} . \mathrm{V}$.

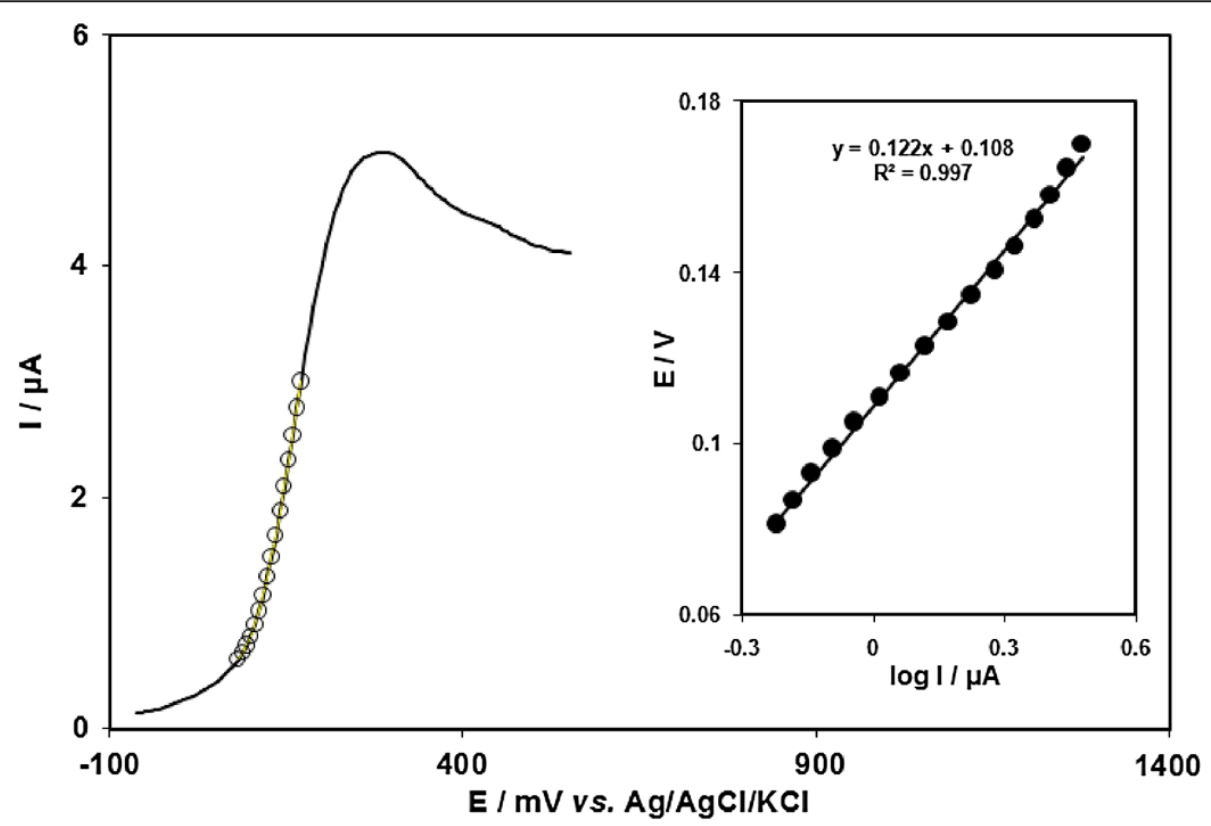

Figure $4 \mathrm{LSV}$ (at $2 \mathrm{mV} \mathrm{s}^{-1}$ ) of a 2,7-BFGPE in $0.1 \mathrm{M} \mathrm{PBS}(\mathrm{pH}$ 7.0) containing $20.0 \mu \mathrm{M}$ methyldopa. The points are the data used in the Tafel plot. The inset shows the Tafel plot derived from the LSV. 


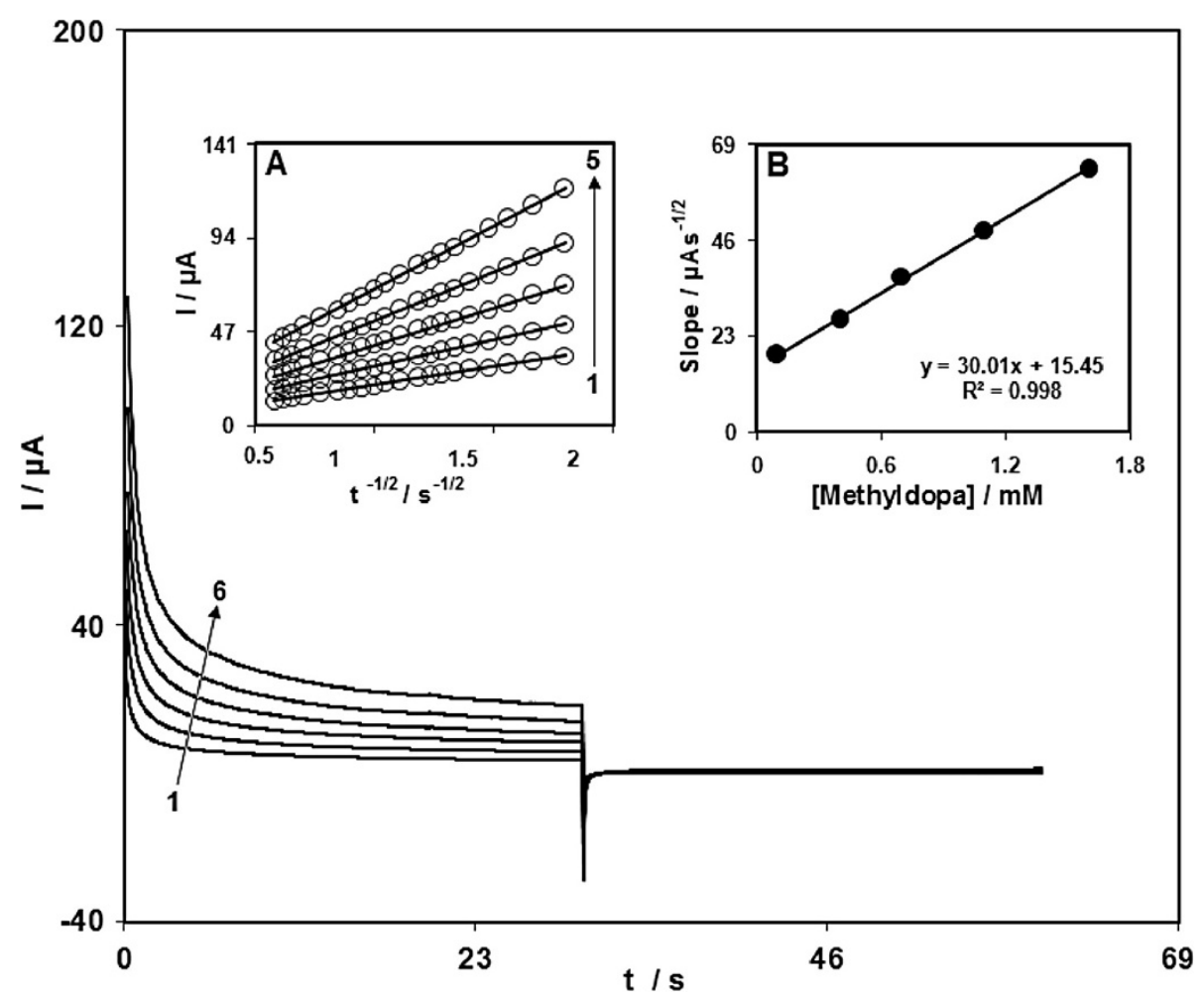

Figure 5 Chronoamperograms obtained at 2,7-BFGPE in 0.1 M PBS (pH 7.0) for different concentrations of methyldopa. Numbers 1 to 6 correspond to $0.0,0.1,0.4,0.7,1.1$, and $1.6 \mathrm{mM}$ of methyldopa, respectively. Insets: (A) Plots of $/ \mathrm{vs} . t^{-1 / 2}$ obtained from chronoamperograms 2 to 6. (B) Plot of the slope of the straight lines against methyldopa concentration.

was unchanged and the current signals showed less than $2.1 \%$ decrease relative to the initial response. The antifouling properties of the modified electrode toward methyldopa oxidation and its oxidation products were investigated by recording the cyclic voltammograms of the modified electrode before and after use in the presence of methyldopa. Cyclic voltammograms were recorded in the presence of methyldopa after having cycled the potential 20 times at a scan rate of $10 \mathrm{mV} \mathrm{s}^{-1}$. The peak potentials were unchanged, and the currents decreased by less than $2.3 \%$. Therefore, at the surface of 2,7-BFGPE, not only the sensitivity increased, but the fouling effect of the analyte and its oxidation product also decreased.

\section{Influence of $\mathrm{pH}$}

The electrochemical behavior of methyldopa is dependent on the $\mathrm{pH}$ value of the aqueous solution, whereas the electrochemical properties of the 2,7-bis(ferrocenyl ethyl) fluoren-9-one/2,7-bis(ferricenium ethyl)fluoren-9-one (Fc/ $\mathrm{Fc}^{+}$) redox couple are independent on $\mathrm{pH}$. Therefore, $\mathrm{pH}$ optimization of the solution seems to be necessary in order to obtain the electrocatalytic oxidation of methyldopa. Thus, the electrochemical behavior of methyldopa was studied in $0.1 \mathrm{M}$ PBS in different $\mathrm{pH}$ values $(2.0<\mathrm{pH}$ $<11.0$ ) at the surface of 2,7-BFGPE by CV. It was found that the electrocatalytic oxidation of methyldopa at the surface of 2,7-BFGPE was more favored under neutral conditions than in acidic or basic medium. This appears as a gradual growth in the anodic peak current and a simultaneous decrease in the cathodic peak current in the CVs of 2,7-BFGPE. Thus, pH 7.0 was chosen as the optimum $\mathrm{pH}$ for electrocatalysis of methyldopa oxidation at the surface of 2,7-BFGPE.

\section{Electrocatalytic oxidation of methyldopa at a 2,7-BFGPE}

Figure 2 depicts the $\mathrm{CV}$ responses for the electrochemical oxidation of $0.35 \mathrm{mM}$ methyldopa at the unmodified CPE (curve b), GPE (curve d), 2,7-BFCPE (curve e), and 2,7-BFGPE (curve f). As it is seen, while the anodic peak potential for methyldopa oxidation at the GPE and unmodified CPE are 480 and $520 \mathrm{mV}$, respectively, the corresponding potential at 2,7-BFGPE and 2,7-BFCPE is approximately $320 \mathrm{mV}$. These results indicate that the peak potential for methyldopa oxidation at 2,7-BFGPE and 2,7-BFCPE shift by approximately 160 and $200 \mathrm{mV}$ toward negative values compared to GPE and unmodified CPE, respectively. However, 2,7-BFGPE shows much higher anodic peak current for the oxidation of methyldopa compared to 2,7-BFCPE, indicating that the combination of $\mathrm{G}$ and the mediator (2,7-BF) has 


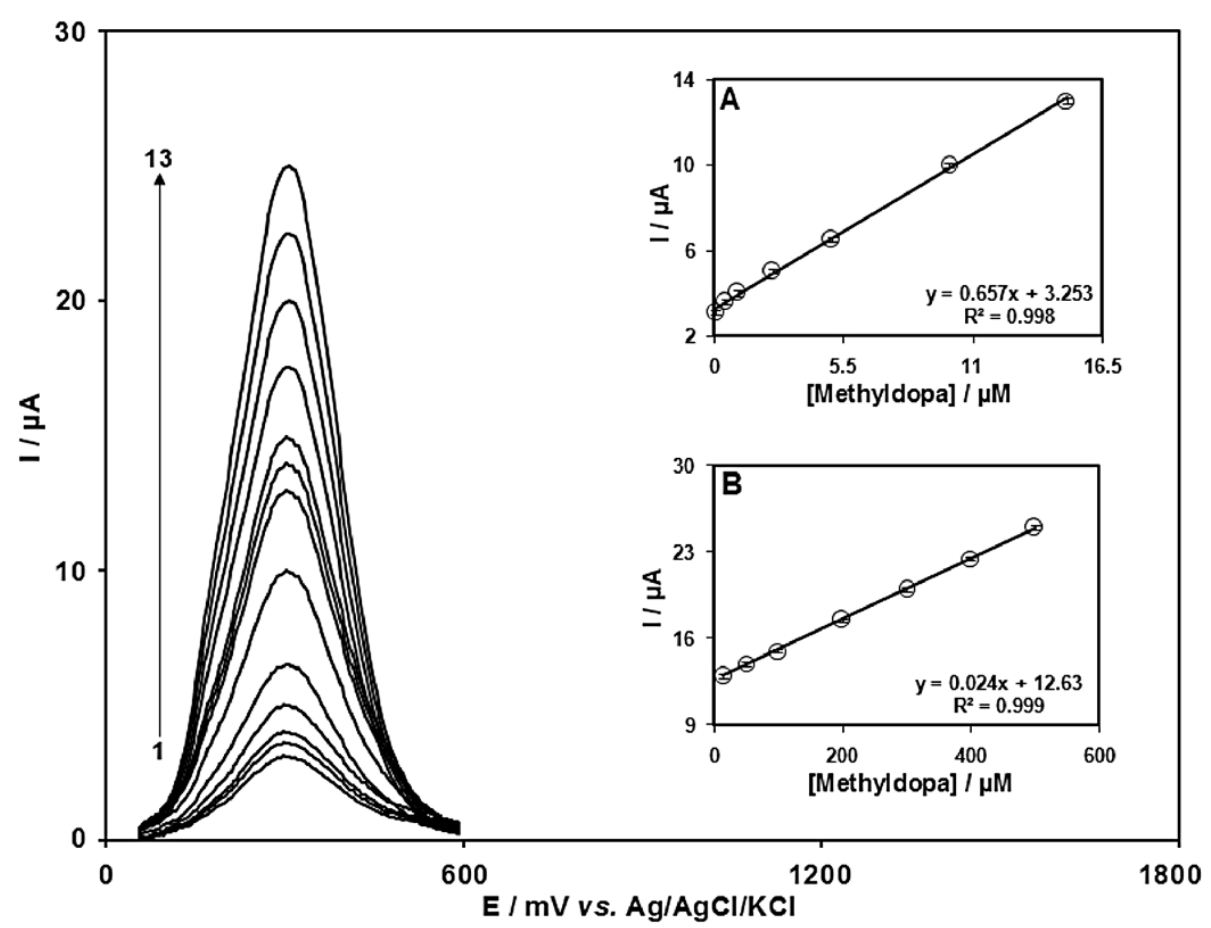

Figure 6 SWVs of 2,7-BFGPE in $0.1 \mathrm{M} \mathrm{PBS}(\mathrm{pH} 7.0)$ containing different concentrations of methyldopa. Numbers 1 to 13 correspond to $0.09,0.5,1.0,2.5,5.0,10.0,15.0,50.0,100.0,200.0,300.0,400.0$, and $500.0 \mu \mathrm{M}$ of methyldopa, respectively. Inset: plots of the electrocatalytic peak current as a function of methyldopa concentration in the range of 0.09 to $15.0 \mu \mathrm{M}$ (A) and 15.0 to $500.0 \mu \mathrm{M}$ (B).

significantly improved the performance of the electrode toward methyldopa oxidation. In fact, 2,7-BFGPE, in the absence of methyldopa, exhibited a well-behaved redox reaction (Figure 2, curve c) in 0.1 M PBS (pH 7.0). However, there was a drastic increase in the anodic peak current in the presence of $0.35 \mathrm{mM}$ methyldopa (curve $\mathrm{f}$ ), which can be related to the strong electrocatalytic effect of 2,7BFGPE toward this compound (Bard and Faulkner 2001).

The effect of scan rate on the electrocatalytic oxidation of methyldopa at 2,7-BFGPE was investigated by linear sweep voltammetry (Figure 3). As can be observed in Figure 3, the oxidation peak potential shifted to more positive potentials with increasing scan rate, confirming the kinetic limitation in the electrochemical reaction. Also, a plot of peak height $\left(I_{\mathrm{p}}\right)$ vs. the square root of scan rate $\left(v^{1 / 2}\right)$ was found to be linear in the range of 2 to $100 \mathrm{mV} \mathrm{s}^{-1}$, suggesting that, at sufficient overpotential, the process is diffusion- rather than surface-controlled (Figure 3A) (Bard and Faulkner 2001). A plot of the scan rate-normalized current $\left(I_{\mathrm{p}} / v^{1 / 2}\right)$ vs. scan rate (Figure $3 \mathrm{~B}$ ) exhibits the characteristic shape typical of an EC process (Bard and Faulkner 2001).

Figure 4 shows the linear sweep voltammograms (LSVs) of an 2,7-BFGPE obtained in 0.1 M PBS (pH 7.0) containing $20.0 \mu \mathrm{M}$ methyldopa, with a sweep rate of $2 \mathrm{mV}$ $\mathrm{s}^{-1}$. The points show the rising part of the voltammogram (known as the Tafel region), which is affected by the electron transfer kinetics between methyldopa and 2,7-BFGPE. If deprotonation of methyldopa is a sufficiently fast step, the number of electrons involved in the rate-determining step can be estimated from the slope of the Tafel plot. The inset of Figure 4 shows a Tafel plot that was drawn from points of the Tafel region of the LSV. The Tafel slope of

Table 1 Comparison of the efficiency of some modified electrodes used in the electrocatalysis of methyldopa

\begin{tabular}{|c|c|c|c|c|c|c|}
\hline Electrode & Modifier & Method & $\mathrm{pH}$ & $\begin{array}{l}\text { Dynamic } \\
\text { range }(\mathrm{M})\end{array}$ & $\begin{array}{l}\text { Limit of } \\
\text { detection (M) }\end{array}$ & Reference \\
\hline Carbon paste & Ferrocene monocarboxylic acid & Voltammetry & 7.0 & $2.0 \times 10^{-7}$ to $1.0 \times 10^{-4}$ & $8.0 \times 10^{-8}$ & Molaakbari et al. (2014) \\
\hline Glassy carbon & Pt-Ru nanoparticles & Voltammetry & 3.0 & $5.0 \times 10^{-8}$ to $4.0 \times 10^{-5}$ & $1.0 \times 10^{-8}$ & $\begin{array}{l}\text { Shahrokhian and } \\
\text { Rastgar (2011) }\end{array}$ \\
\hline Carbon paste & Cellulose acetate/ionic liquids & Voltammetry & 5.5 & $3.48 \times 10^{-5}$ to $3.7 \times 10^{-4}$ & $5.5 \times 10^{-6}$ & Moccelini et al. (2011) \\
\hline Carbon nanotube paste & $5 A E B$ & Voltammetry & 8.0 & $1.0 \times 10^{-7}$ to $2.1 \times 10^{-4}$ & $4.8 \times 10^{-8}$ & Tajik et al. (2013a) \\
\hline Graphene paste & $2,7-B F$ & Voltammetry & 7.0 & $8.0 \times 10^{-8}$ to $5.0 \times 10^{-4}$ & $5.0 \times 10^{-8}$ & This work \\
\hline
\end{tabular}


Table 2 The application of 2,7-BFGPE for determination of methyldopa in methyldopa tablet and urine samples

\begin{tabular}{lccccc}
\hline Sample & $\begin{array}{c}\text { Original } \\
\text { content }\end{array}$ & Spiked & Found & Recovery (\%) & R.S.D. (\%) \\
\hline Methyldopa & & & & & \\
tablet & 15.0 & 0 & 15.3 & 102.0 & 3.5 \\
& 15.0 & 5.0 & 19.8 & 99.0 & 1.9 \\
& 15.0 & 1.0 & 24.4 & 97.6 & 2.5 \\
& 15.0 & 15.0 & 30.5 & 101.7 & 2.9 \\
Urine & & & & & \\
& - & 7.5 & 7.4 & 98.7 & 1.8 \\
& - & 12.5 & 12.9 & 103.2 & 3.1 \\
& - & 17.5 & 17.4 & 99.4 & 2.3 \\
& - & 22.5 & 23.1 & 102.7 & 2.6 \\
\hline
\end{tabular}

All concentrations are in micromolar $(n=5)$.

$0.122 \mathrm{~V}$ obtained in this case agrees well with the involvement of one electron in the rate-determining step of the electrode process, assuming a charge transfer coefficient of $\alpha=0.52$ (Bard and Faulkner 2001).

\section{Chronoamperometric measurements}

Chronoamperometric measurements of methyldopa at 2,7BFGPE were carried out by setting the working electrode potential at $0.4 \mathrm{~V}$ (at the first potential step) and at $0.1 \mathrm{~V}$ (at the second potential step) vs. $\mathrm{Ag} / \mathrm{AgCl} / \mathrm{KCl}(3.0 \mathrm{M}$ ) for the various concentrations of methyldopa in buffered aqueous solutions (pH 7.0) (Figure 5). For an electroactive material (methyldopa in this case) with a diffusion coefficient of $D$, the current observed for the electrochemical reaction at the mass transport-limited condition is described by the Cottrell equation (Bard and Faulkner 2001). Experimental plots of $I$ vs. $t^{-1 / 2}$ were employed, with the best fits for different concentrations of methyldopa (Figure 5A). The slopes of the resulting straight lines were then plotted vs. the methyldopa concentration (Figure 5B). From the resulting slope and Cottrell equation, the mean value of $D$ was found to be $9.35 \times 10^{-6} \mathrm{~cm}^{2} \mathrm{~s}^{-1}$.

\section{Calibration plot and limit of detection}

The Square Wave Voltammetry (SWV) method was used to determine the concentration of methyldopa (initial potential $=0.06 \mathrm{~V}$, end potential $=0.6 \mathrm{~V}$, step potential $=$ $0.001 \mathrm{~V}$, amplitude $=0.02 \mathrm{~V}$, frequency $=10 \mathrm{~Hz}$ ) (Figure 6). The plot of peak current vs. methyldopa concentration consisted of two linear segments with slopes of 0.657 and $0.024 \mu \mathrm{A} \mu \mathrm{M}^{-1}$ in the concentration ranges of 0.09 to $15.0 \mu \mathrm{M}$ and 15.0 to $500.0 \mu \mathrm{M}$, respectively. The decrease in sensitivity (slope) of the second linear segment is likely due to kinetic limitation (Bard and Faulkner 2001). The detection limit $(3 \sigma)$ of methyldopa was found to be 50.0 $\mathrm{nM}$. These values are comparable with values reported by other research groups for electrocatalytic oxidation of methyldopa at the surface of chemically modified electrodes by other mediators (Table 1).

\section{Interference studies}

The influence of various substances as compounds potentially interfering with the determination of methyldopa was studied under optimum conditions. The potentially interfering substances were chosen from the group of substances commonly found with methyldopa in pharmaceuticals and/or in biological fluids. The tolerance limit was defined as the maximum concentration of the interfering substance that caused an error of less than $\pm 5 \%$ in the determination of methyldopa. According to the results, L-lysine, glucose, NADH, acetaminophen, uric acid, L-asparagine, L-serine, L-threonine, L-proline, L-histidine, L-glycine, L-tryptophan, L-phenylalanine, lactose, saccharose, fructose, benzoic acid, methanol, ethanol, urea, caffeine, $\mathrm{Mg}^{2+}, \mathrm{Al}^{3+}, \mathrm{NH}_{4}^{+}, \mathrm{Fe}^{2+}, \mathrm{Fe}^{3+}, \mathrm{F}^{-}, \mathrm{SO}_{4}^{2-}$, and $\mathrm{S}^{2-}$ did not show interference in the determination of methyldopa. However, levodopa, carbidopa, dopamine, and ascorbic acid with equal molar concentration make interference. Although ascorbic acid showed interference, this interference could be minimized, if necessary, by using ascorbic oxidase enzyme, which exhibits a high selectivity to the oxidation of ascorbic acid.

\section{Real sample analysis \\ Determination of methyldopa in methyldopa tablet and urine samples}

In order to evaluate the analytical applicability of the proposed method, it was also applied for the determination of methyldopa in methyldopa tablet (each tablet containing $250 \mathrm{mg}$ methyldopa from Darou-Pakhsh, Tehran, Iran). The results for determination of methyldopa in the methyldopa tablet are given in Table 2. Satisfactory recovery of the experimental results was found for methyldopa. The reproducibility of the method was demonstrated by the mean relative standard deviation (R.S.D.).

Also, in order to evaluate the analytical applicability of the proposed method, it was applied for the determination of methyldopa in urine samples. Known amounts of methyldopa were added to the urine sample, and its concentrations were estimated with the proposed method. The urine sample was found to be free from methyldopa. Therefore, different amounts of methyldopa were spiked to the sample and analyzed by the proposed method. The results for determination of methyldopa in real samples are given in Table 2 . Satisfactory recovery of the experimental results was found for methyldopa. The reproducibility of the method was demonstrated by the mean R.S.D.

\section{Conclusions}

2,7-BFGPE was prepared and used for the investigation of the electrochemical behavior of methyldopa. Two pairs of 
well-defined redox peaks were obtained at 2,7-BFGPE. 2,7-BFGPE showed excellent electrocatalytic activity for the redox of methyldopa. Compared with the bare electrode, the oxidation current of methyldopa increased greatly and the oxidation peak potential shifted negatively by $200 \mathrm{mV}$. This sensor showed a wide linear range $(0.09$ to $500.0 \mu \mathrm{M})$ with good detection limit $(0.05 \mu \mathrm{M})$ for methyldopa. This sensor was successfully applied to determine methyldopa in some real samples.

\section{Competing interests}

The authors declare that they have no competing interests.

\section{Authors' contributions}

Hadi Beitollahi, Somayeh Tajik and Hossein Asadi performed the fields of experimental sections and analysis of data. Pourya Biparva synthesized the graphene nanosheets. All authors read and approved the final manuscript.

\section{Author details}

${ }^{1}$ Environment Department, Institute of Science and High Technology and Environmental Sciences, Graduate University of Advanced Technology, P.O. Box 76315-117, Kerman, Iran. ${ }^{2}$ Department of Chemistry, Shahid Bahonar University of Kerman, P.O. Box 76175-133, Kerman, Iran. ${ }^{3}$ Biotechnology Department, Institute of Science and High Technology and Environmental Sciences, Graduate University of Advanced Technology, P.O. Box 76315-117, Kerman, Iran. ${ }^{4}$ Department of Basic Sciences, Sari Agricultural Sciences and Natural Resources University, P.O. Box 79316-217, Sari, Iran.

Received: 7 January 2014 Accepted: 17 March 2014

Published online: 28 May 2014

\section{References}

Athanasiou-Malaki EM, Koupparis MA (1984) Indirect potentiometric determination of a-amino acids with a copper-selective electrode and determination of dopa and methyldopa in pharmaceutical preparations. Anal Chim Acta 161:349

Bard AJ, Faulkner LR (2001) Electrochemical methods: fundamentals and applications, 2nd edition. Wiley, New York

Beitollahi H, Raoof JB, Hosseinzadeh R (2011a) Application of a carbon-paste electrode modified with 2,7-bis(ferrocenyl ethyl)fluoren-9-one and carbon nanotubes for voltammetric determination of levodopa in the presence of uric acid and folic acid. Electroanalysis 23:1934

Beitollahi H, Raoof JB, Hosseinzadeh R (2011 b) Electroanalysis and simultaneous determination of 6 -thioguanine in the presence of uric acid and folic acid using a modified carbon nanotube paste electrode. Anal Sci 27:991

Beitollahi H, Taher MA, Ahmadipour M, Hosseinzadeh R (2014c) Electrocatalytic determination of captopril using a modified carbon nanotube paste electrode: application to determination of captopril in pharmaceutical and biological samples. Measurement 47:770

Díaz C, García C, Iturriaga-Vásquez P, Jesús Aguirre M, Pablo Muena J, Contreras R, Ormazábal-Toledo R, Isaacs M (2013) Experimental and theoretical study on the oxidation mechanism of dopamine in n-octyl pyridinium based ionic liquids-carbon paste modified electrodes. Electrochimi Acta 111:846

Dönmez S, Arslan F, Sarı N, Kurnaz Yetim N, Arslan H (2014) Preparation of carbon paste electrodes including poly(styrene) attached glycine-Pt(IV) for amperometric detection of glucose. Biosens Bioelectron 54:146

Gholivand MB, Amiri M (2013) Highly sensitive and selective determination methyldopa in the presence of ascorbic acid using OPPy/TY/Au modified electrode. J Electroanal Chem 694:56

Gholivand MB, Mohammadi-Behzad L (2014) Fabrication of a highly sensitive sumatriptan sensor based on ultrasonic-electrodeposition of Pt nanoparticles on the $\mathrm{ZrO}_{2}$ nanoparticles modified carbon paste electrode. J Electroanal Chem 712:33

Ghoreishi SM, Behpour M, Golestaneh M (2012) Simultaneous determination of Sunset yellow and Tartrazine in soft drinks using gold nanoparticles, carbon paste electrode. Food Chem 132:637

Hummers WS, Offeman RE (1958) Preparation of graphitic oxide. J Am Chem Soc 80:1339
Huo J, Shangguan E, Li Q (2013) A pre-anodized inlaying ultrathin carbon paste electrode for simultaneous determination of uric acid and folic acid. Electrochim Acta 89:600

Joon OY, Yoo JJ, Kim Y, II YJK, Yoon HN, Kim JH, Bin Park S (2014) Oxygen functional groups and electrochemical capacitive behavior of incompletely reduced graphene oxides as a thin-film electrode of supercapacitor. Electrochim Acta 116:118

Khoobi A, Ghoreishi SM, Masoum S, Behpour M (2013) Multivariate curve resolution-alternating least squares assisted by voltammetry for simultaneous determination of betaxolol and atenolol using carbon nanotube paste electrode. Bioelectrochemistry 94:100

Kwan KC, Foltz EL, Breault GO, Baer JE, Totaro JA (1976) Pharmacokinetics of methyldopa in man. J Pharmacol Exp Ther 198:264

Li BL, WuZ L, Xiong CH, Luo HQ, Li NB (2012) Anodic stripping voltammetric measurement of trace cadmium at tin-coated carbon paste electrode. Talanta 88:707

Luo JH, Jiao XX, Li NB, Luo HQ (2013) Sensitive determination of Cd(II) by square wave anodic stripping voltammetry with in situ bismuth-modified multiwalled carbon nanotubes doped carbon paste electrodes. J Electroanal Chem 689:130

Ma J, Zhou L, Li C, Yang J, Meng T, Zhou H, Yang M, Yu F, Chen J (2014) Surfactant-free synthesis of graphene-functionalized carbon nanotube film as a catalytic counter electrode in dye-sensitized solar cells. J Power Sour 247:999

Mazloum-Ardakani M, Beitollahi H, Amini MK, Mirkhalaf F, Abdollahi-Alibeik M (2010) New strategy for simultaneous and selective voltammetric determination of norepinephrine, acetaminophen and folic acid using $\mathrm{ZrO}_{2}$ nanoparticlesmodified carbon paste electrode. Sens. Actuators B 151:243

Moccelini SK, Franzoi AC, Vieira IC, Dupont J, Scheeren CW (2011) A novel support for laccase immobilization: cellulose acetate modified with ionic liquid and application in biosensor for methyldopa detection. Biosens Bioelectron 26:3549

Mohammadi S, Beitollahi H, Mohadesi A (2013) Electrochemical behaviour of a modified carbon nanotube paste electrode and its application for simultaneous determination of epinephrine, uric acid and folic acid. Sensor Lett 11:388

Mokhtari A, Karimi-Maleh H, Ensafi AA, Beitollahi H (2012) Application of modified multiwall carbon nanotubes paste electrode for simultaneous voltammetric determination of morphine and diclofenac in biological and pharmaceutical samples. Sens Actuators B 169:96

Molaakbari E, Mostafavi A, Beitollahi H (2014) First report for voltammetric determination of methyldopa in the presence of folic acid and glycine. Mater Sci Engin C 36:168-172

Myhre E, Rugstad HE, Hansen T (1982) Clinical pharmacokinetics of methyldopa. Clin Pharmacokinet 7:221

Oliveira KM, Santos TCC, Dinelli LR, Marinho JZ, Lima RC, Bogado AL (2013) Aggregates of gold nanoparticles with complexes containing ruthenium as modifiers in carbon paste electrodes. Polyhedron 50:410

Ping J, Wang Y, Wu J, Ying Y (2014) Development of an electrochemically reduced graphene oxide modified disposable bismuth film electrode and its application for stripping analysis of heavy metals in milk. Food Chem 151:65

Raoof JB, Ojani R, Beitollahi H, Hossienzadeh R (2006a) Electrocatalytic determination of ascorbic acid at the surface of 2,7-bis(ferrocenyl ethyl) fluoren-9-one modified carbon paste electrode. Electroanalysis 18:1193

Raoof JB, Ojani R, Beitollahi H, Hosseinzadeh R (2006b) Electrocatalytic oxidation and highly selective voltammetric determination of $\mathrm{L}$-cysteine at the surface of a 1-[4-(ferrocenyl ethynyl)phenyl]-1-ethanone modified carbon paste electrode. Anal Sci 22:1213

Raoof JB, Ojani R, Beitollahi H (2007) L-cysteine voltammetry at a carbon paste electrode bulk-modified with ferrocenedicarboxylic acid. Electroanalysis 19:1822

Rezaei B, Askarpour N, Ensafi AA (2013) Adsorptive stripping voltammetry determination of methyldopa on the surface of a carboxylated multiwall carbon nanotubes modified glassy carbon electrode in biological and pharmaceutical samples. Colloids Surf B 109:53

Sanghavi BJ, Mobin SM, Mathur P, Lahiri GK, Srivastava AK (2013) Biomimetic sensor for certain catecholamines employing copper(II) complex and silver nanoparticle modified glassy carbon paste electrode. Biosens Bioelectron 39:124

Shahrokhian S, Rastgar S (2011) Electrodeposition of Pt-Ru nanoparticles on multi-walled carbon nanotubes: application in sensitive voltammetric determination of methyldopa. Electrochim Acta 58:125

Silva H, Pacheco JG, Magalhães JMCS, Viswanathan S, Delerue-Matos C (2014) MIP-graphene-modified glassy carbon electrode for the determination of trimethoprim. Biosens Bioelectron 52:56-61 
Sun W, Wang Y, Zhang Y, Ju X, Li G, Sun Z (2012) Poly(methylene blue) functionalized graphene modified carbon ionic liquid electrode for the electrochemical detection of dopamine. Anal Chim Acta 751:59

Tajik S, Taher MA, Beitollahi H (2013a) First report for simultaneous determination of methyldopa and hydrochlorothiazide using a nanostructured based electrochemical sensor. J Electroanal Chem 704:137

Tajik S, Taher MA, Beitollahi H (2013b) Simultaneous determination of droxidopa and carbidopa using a carbon nanotubes paste electrode. Sens Actuators B 188:923

Taleat Z, Mazloum Ardakani M, Naeimi H, Beitollahi H, Nejati M, Zare HR (2008) Electrochemical behavior of ascorbic acid at a 2,2'-[3,6-dioxa-1,8-octanediylbis (nitriloethylidyne)]-bis-hydroquinone carbon paste electrode. Anal Sci 24:1039

Thomas T, Mascarenhas RJ, Cotta F, Guha KS, Kumara Swamy BE, Martis P, Mekhalif Z (2013a) Poly(Patton and Reeder's reagent) modified carbon paste electrode for the sensitive detection of acetaminophen in biological fluid and pharmaceutical formulations. Colloids Surf B 101:91

Thomas T, Mascarenhas RJ, D'Souza OJ, Martis P, Dalhalle J, Kumara Swamy BE (2013b) Multi-walled carbon nanotube modified carbon paste electrode as a sensor for the amperometric detection of L-tryptophan in biological samples. J Colloid Interf Sci 402:223

Thomas T, Mascarenhas RJ, Kumara Swamy BE, Martis P, Mekhalif Z, Sherigara BS (2013c) Multi-walled carbon nanotube/poly(glycine) modified carbon paste electrode for the determination of dopamine in biological fluids and pharmaceuticals. Colloids Surf B 110:458

Xi F, Zhao D, Wang X, Chen P (2013) Non-enzymatic detection of hydrogen peroxide using a functionalized three-dimensional graphene electrode. Electrochem Commun 26:81

Yildiz G, Oztekin N, Orbay A, Senkal F (2014) Voltammetric determination of nitrite in meat products using polyvinylimidazole modified carbon paste electrode. Food Chem 152:245

Zhu W, Chen T, Ma X, Ma H, Chen S (2013) Highly sensitive and selective detection of dopamine based on hollow gold nanoparticles-graphene nanocomposite modified electrode. Colloids Surfaces B 111:321

doi:10.1186/s40543-014-0029-y

Cite this article as: Beitollahi et al: Application of a modified graphene nanosheet paste electrode for voltammetric determination of methyldopa in urine and pharmaceutical formulation. Journal of Analytical Science and Technology 2014 5:29.

\section{Submit your manuscript to a SpringerOpen ${ }^{\circ}$ journal and benefit from:}

- Convenient online submission

- Rigorous peer review

- Immediate publication on acceptance

- Open access: articles freely available online

- High visibility within the field

- Retaining the copyright to your article

Submit your next manuscript at $\gg$ springeropen.com 